\title{
Solidification of Additive-Enhanced Phase Change Materials in Spherical Enclosures with Convective Cooling
}

\author{
Mikail Temirel, Han Hu, Hamidreza Shabgard, Philipp Boettcher, Matthew McCarthy, Ying \\ Sun $^{*}$ \\ Department of Mechanical Engineering and Mechanics, Drexel University, Philadelphia, PA \\ 19104, USA
}

\begin{abstract}
Solidification of eicosane with and without nanoadditives is experimentally investigated in spherical enclosures subject to convective cooling in water and air. The effects of additive volume fraction and external convective cooling conditions (i.e., the heat transfer medium, subcooling, and flow velocity) on the solidification process are examined. The results are compared with a conduction-controlled thermal network model accounting for the enclosure and PCM resistances, as well as the convective subcooling. The experimentally determined solidification time is found to be consistently lower than the model prediction, likely due to asymmetric and dendritic solidification, as well as natural convection inside the enclosure and possible thermocouple position errors. A simple correlation is proposed to predict the solidification time of a phase change material (PCM) in a spherical enclosure subject to convective cooling based on the same enclosure subject to a constant temperature boundary. Results show that the solidification time decreases with the volume fraction of nanoadditives due to the improved PCM conductivity. In addition, the nanoadditives are found to be more effective for solidification in water than in air, due to the large air-side convective resistance that does not benefit from improving PCM conductivity.
\end{abstract}

Keywords: Phase change materials, nanoadditives, solidification, convective cooling

*Corresponding author. Tel.:+1-215-895-1373; fax: +1-215-895-1478; Email: ysun@coe.drexel.edu. 


\section{Introduction}

Phase change materials (PCMs), due to their ability to transfer large amounts of heat in a narrow temperature range, are well suited for thermal management systems with mismatching supply and demand thermal loads as well as thermal energy storage systems. Among various configurations, melting and solidification in spherical enclosures is encountered in many applications such as chemical reactors [1], packed bed latent heat energy storage [2], spray freezing $[3,4]$ and advanced PCM slurry heat transfer fluids $[5,6]$.

For several decades, many investigators have modeled the solidification in spherical enclosures. Tao [7] developed a numerical model to investigate the effect of external convection and sensible heat removal from the solidified layer during spherical freezing. Pedroso and Domoto [8] solved the problem of inward spherical solidification subject to a constant wall temperature using a perturbation method. Ismail and Henriquez [9] developed an analytical model for inward solidification in a spherical enclosure subject to either the constant temperature or the convection heat transfer condition on the external surface of the spherical shell. Hill and Kucera [10] utilized a semi-analytical procedure to investigate the inward solidification in a spherical container with the effect of radiation. Wu et al. [11] used the small-time series expansion technique to solve the unsteady heat equation where the effect of curvature on the interface temperature is included. Lin and Jiang [12] used a quasi-steady model for solidification in spherical enclosures with an additional term to account for the transient effect on the

temperature distribution. Riley et al. [13] presented an analytical study for inward freezing of a sphere with a two-region analysis to accommodate the singularity at the center of the sphere. McCue at al. [14] developed a model for spherical solidification of superheated PCMs under a constant temperature boundary condition. It was found that, at the first stage of solidification, the temperature in both solid and liquid phases depends on the inverse Stefan number, but at later times the inner liquid core contributes insignificantly to the location of the solidification front [14].

In addition to the mathematical models, experimental and numerical studies have also been performed to investigate the solidification of spherical PCM. Chan and Tan [15] experimentally studied the effects of cooling water temperature and initial PCM superheating on the solidification rate of $n$-hexadecane in spherical shells. It was shown that the solidification rate increases by decreasing the cooling water temperature, while the effect of initial superheating of 
the liquid PCM is negligible. In a related work, Assis et al. [16] experimentally studied the solidification of a commercial PCM in spherical capsules that were cut at various times to measure the thickness of the solid layer. The morphology of the solidification front was compared with the predictions of their numerical model and a good agreement was observed. A similar experimental study was conducted by Eames and Adref [17] to characterize the freezing and melting processes of deionized water. The solidification rate was determined using the changes in air pressure in the PCM enclosure upon phase change, where it was found that $90 \%$ of the total phase change occurs in the first $70 \%$ of the total phase change time. Ismail et al. [9] developed a conduction-controlled model to numerically investigate the effect of spherical shell material and size, wall thickness, initial PCM temperature, external fluid temperature, and Biot number on solidification of PCMs in spherical enclosures. The thermal conductivity of the shell material was found to significantly affect the solidification time.

In order to take full advantage of the high energy density of PCMs, the low thermal conductivity of most PCMs must be overcome. Efforts have been made to improve the phase change rates in spherical PCM enclosures by using extended surfaces [18] and dispersion of metallic beads within the PCM [19]. Experimental results by Koizumi [18] showed that insertion of copper fins inside a spherical container reduces the $n$-octadecane melting time by $33 \%$. Ettouney et al. [19] conducted experiments to assess the effect of stainless steel beads dispersed within paraffin wax on melting and solidification rates in a $30 \mathrm{~mm}$ spherical shell. It was found that total phase change time is reduced by $15 \%$, equivalent to the PCM mass replaced by metallic balls, suggesting negligible improvement for the enclosure size employed. Recently, carbonbased nanoadditives, such as graphite nanofibers [20], exfoliated graphite nanoplatelets (xGnPs) $[21,22]$, and ultrathin graphite foams [23] have been utilized to enhance the thermal conductivity of PCMs. Kalaiselvam et al. [24] conducted experiments on solidification of six types of nanoadditive-enhanced PCMs in spherical capsules under constant wall temperature conditions and reported up to $22 \%$ decrease in solidification time compared to that of the pure PCM. They also found that increasing the mass fraction of nanoadditives beyond $7 \%$ does not result in further reduction in solidification time. Chandrasekaran et al. [25] experimentally studied solidification of water-based copper oxide nanofluid in a spherical capsule subject to constant wall temperature conditions and reported $35 \%$ reduction in solidification time compared to pure water. It was also shown that $50 \%$ of the PCM mass is solidified in only $25 \%$ of the total 
freezing time. In a similar study, Kumaresan et al. [26] conducted experiments on solidification of water-based carbon nanotube nanofluid encapsulated in a spherical shell and observed $20 \%$ reduction in solidification time compared to pure water. Altohamy et al. [27] reported experimental results on solidification time of water-based alumina nanofluid in a spherical capsule subject to a constant wall temperature where up to $30 \%$ reduction in solidification time was achieved for $2 \%$ additive volume fraction.

Review of the literature reveals that most of the analytical and in particular experimental studies have been focused on solidification under constant temperature conditions. However, the majority of the aforementioned applications pertaining to spherical solidification involve convective heat transfer between an external heat transfer fluid and the PCM. One fundamental difference between the constant temperature and convective boundary conditions is that for the former the PCM itself presents the major thermal resistance prevailing the heat transfer. However, for convective cooling, the thermal resistance due to external convection may be comparable or even greater than the PCM thermal resistance. The relative magnitude of the internal (PCM) and external resistances determines the proper choice of heat transfer enhancement to be employed. In this work, solidification of eicosane with $\mathrm{xGnP}$ of varying volume fractions in spherical enclosures of 38 and $50 \mathrm{~mm}$ is experimentally investigated under constant temperature (submerged in water) and convective cooling (exposed to air flow) boundary conditions. The effects of additive volume fraction, convective subcooling, and external heat transfer coefficient on solidification time are studied. A conduction-controlled thermal network model is developed for the solidification process, and the model predictions are compared with the experimental results. A correlation is proposed to predict the PCM solidification time in a spherical enclosure subject to convective cooling as a function of the Biot number and the solidification time of the same enclose with a constant wall temperature.

\section{Methodology}

\subsection{Solidification of PCM}

As one of the most popular PCMs, eicosane has been used in many experimental studies on PCM thermal properties and phase change behavior [21,28-31]. In the present study, n-eicosane (99\%, Sigma Aldrich) is used as the PCM, with a melting point of $36.4{ }^{\circ} \mathrm{C}$, heat of fusion of 
$247.3 \mathrm{~kJ} / \mathrm{kg}$, solid density of $815 \mathrm{~kg} / \mathrm{m}^{3}$, liquid density of $780 \mathrm{~kg} / \mathrm{m}^{3}$, solid specific heat of 1.92 $\mathrm{kJ} /(\mathrm{kg} \cdot \mathrm{K})$, and liquid specific heat of $2.46 \mathrm{~kJ} /(\mathrm{kg} \cdot \mathrm{K})$ [32]. Two sets of solidification experiments were conducted for nanoadditive-enhanced eicosane in spherical enclosures under constant wall temperature and convective cooling conditions, respectively. The constant temperature tests were performed by submerging the PCM enclosures in a temperature-controlled water bath with forced convection (Fig. 1a). For convective cooling tests, the PCM enclosures were placed in a wind tunnel with precise control of the air velocity (Fig. 1b). Stainless steel spherical enclosures with outer diameters of $50 \mathrm{~mm}$ and $38 \mathrm{~mm}$ and respective wall thicknesses of $2 \mathrm{~mm}$ and $3 \mathrm{~mm}$ were employed. A thermocouple rake was inserted into the spherical enclosure to measure the temperature distribution of the PCM during solidification. The insets of Fig. 2a and $2 b$ show the thermocouple configurations in the $38 \mathrm{~mm}$ diameter sphere and the $50 \mathrm{~mm}$ diameter sphere, respectively. Two T-type thermocouples (labeled as TC1 and TC2 in the inset of Fig. 2a) were used in the thermocouple rake in the $38 \mathrm{~mm}$ diameter sphere: one in the geometric center of the sphere, and one on the inner surface of the shell. Five T-type thermocouples (labeled as TC1 to TC5 in the inset of Fig. 2b) were used in the thermocouple rake in the $50 \mathrm{~mm}$ diameter sphere: TC1 and TC5 were located at the center and on the inner surface of the sphere, respectively; TC2, TC3, and TC4 were located between TC1 and TC5 with spacing of $s_{12}=s_{23}=s_{34}=6 \mathrm{~mm}$, and $s_{45}=5 \mathrm{~mm}$. The thermocouples were connected to an Omega Engineering 8-channel OM$\mathrm{CP}$ data logger to record the temperature history. The spherical enclosures filled with PCM are initially submerged in a hot water bath at a temperature of $60^{\circ} \mathrm{C}$ (well above the melting point of tested PCM) to keep the PCM in liquid state. After thermal equilibrium is reached the PCM spheres are moved to the chiller/wind tunnel to conduct the water/air cooling tests. Once the thermal boundary condition is established the data logger starts to record the temperature history at various locations within the PCM. 
(a)

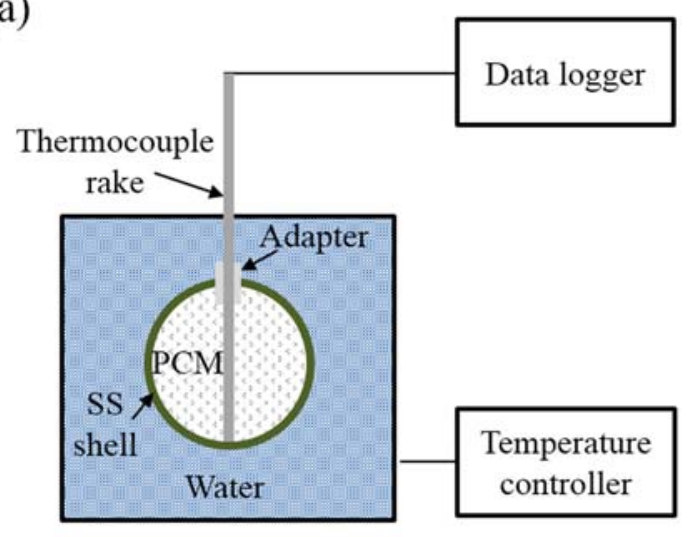

(b)

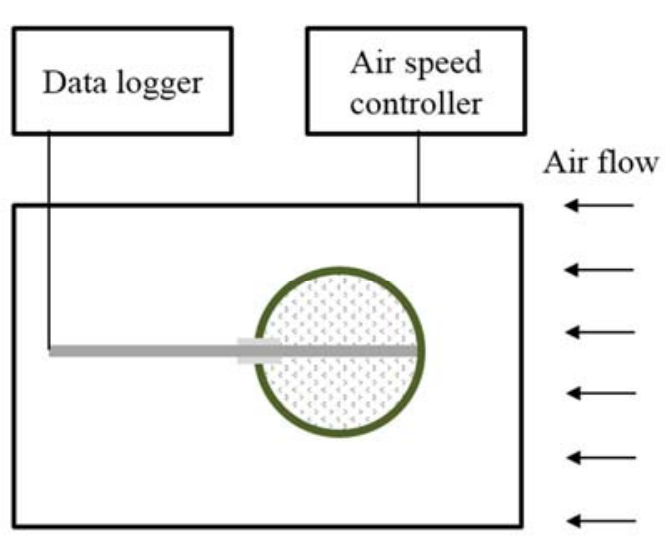

Figure 1. Schematic of the experimental setup for solidification of PCM subject to (a) water cooling (i.e., constant wall temperature case) and (b) air cooling (i.e., convective cooling case).

Figures $2 \mathrm{a}$ and $2 \mathrm{~b}$ show the example temperature histories during solidification of PCM subject to air cooling at $T_{\text {air }}=25{ }^{\circ} \mathrm{C}$ and $U_{\text {air }}=25 \mathrm{~m} / \mathrm{s}$ in $38 \mathrm{~mm}$ and $50 \mathrm{~mm}$ diameter spheres, respectively. As shown in Fig. 2a, the PCM is initially superheated, and its temperature decreases quickly after the cooling process starts at $t=0$. The complete solidification time is determined using the temperature measurement at the inner surface (TC2) and the center (TC1). After cooling starts $(t=0)$, the temperatures at both the inner surface and the center of the sphere drop rapidly. The inflection of the temperature profile at the inner surface (measured by TC2) represents the onset of solidification. The temperature at the center (TC1) also shows an inflection shortly after cooling starts, then remains fairly flat for an extended period of time, and starts to drop rapidly again (showing a second inflection in the curve), indicating the end of phase change. The solidification time is calculated as the time between the inflection of the inner surface temperature (measured by $\mathrm{TC} 2$ ) and the second inflection of the center temperature (measured by TC1), as labeled in Fig. 2a. The greater number of thermocouples in the larger sphere allows for the determination of partial solidification time, where solid volume fractions of $100 \%, 98 \%, 86 \%$, and $52 \%$ can be measured based on the readings of TC1 to TC4, respectively. 
(a)

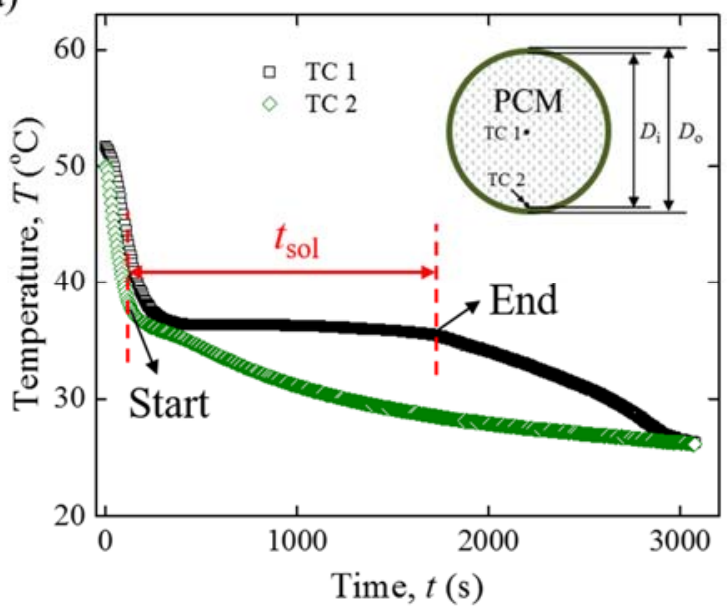

(b)

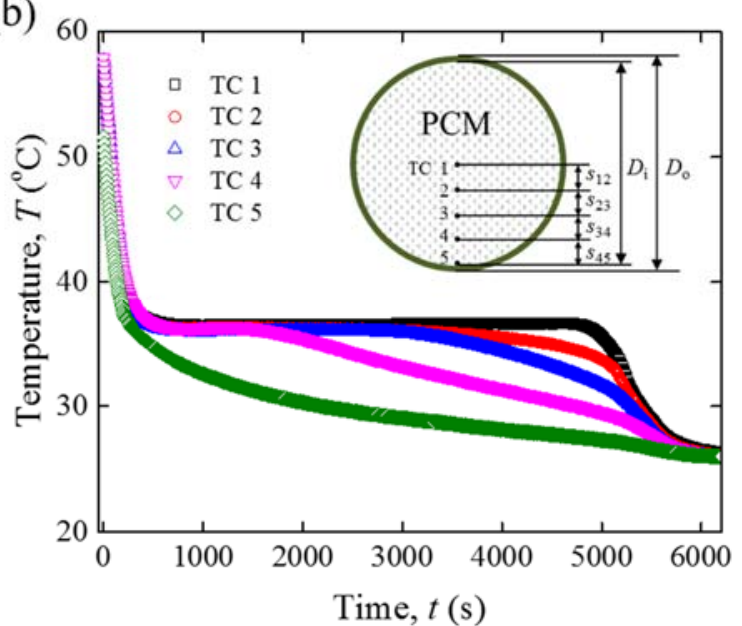

Figure 2. (a) Time history of the temperature of the inner surface and PCM temperature at the center temperatures during solidification of eicosane in spherical enclosure with an outer diameter of $38 \mathrm{~mm}$, (b) Temperature history during solidification of eicosane at various radial locations for solidification of eicosane in spherical enclosures with an outer diameter of $50 \mathrm{~mm}$. Both experiments are performed in air at $T_{\text {air }}=25{ }^{\circ} \mathrm{C}$ and $U_{\text {air }}=25 \mathrm{~m} / \mathrm{s}$. Insets show the configuration of thermocouples.

\subsection{Thermal conductivity measurement of PCM}

While the heat of fusion of paraffin-based PCMs is reasonably high $(\sim 150-250 \mathrm{~kJ} / \mathrm{kg})$, the thermal conductivity of these PCMs is usually low $(\sim 0.1-0.4 \mathrm{~W} /(\mathrm{m} \cdot \mathrm{K}))$. The low conductivity of the PCM may lead to large conductive resistance for heat transfer. Experimental studies have shown enhancement in effective thermal conductivity of PCMs with a variety of nano-additives. One of the objectives of the present work is to investigate how nanoadditive concentration affects the effective thermophysical properties of the additive-enhanced PCM. Exfoliated graphite nanoplatelets (xGnPs) from XG Science was used in this study as a thermal enhancement agent dispersed in eicosane, due to its high thermal conductivity and relative low cost and density. The xGnPs used in this work were of $25 \mu \mathrm{m}$ average diameter and $15 \mathrm{~nm}$ average thickness with an effective thermal conductivity of about $98 \mathrm{~W} /(\mathrm{m} \cdot \mathrm{K})$ [33].

The thermal conductivity of the additive-enhanced PCM was measured using the hot wire method that is suitable for conductivity measurement of low thermal conductivity materials [1618]. The hot wire method is based on transient one-dimensional cylindrical heat conduction in 
the tested material. The thermal conductivity of the tested material is determined based on onedimensional transient cylindrical heat condition as

$$
k=\frac{q}{4 \pi L} \frac{d \ln (t)}{d \Delta T}
$$

where $q$ is heat flow rate applied to the wire, $L$ is the length of the wire, $t$ is the time, and $\Delta T$ is the transient temperature increase of the hot wire after being subjected to the heat flow $q$, defined following $\Delta T(t)=T_{\text {wire }}(t)-T_{\text {wire }}(0)$, where $t=0$ represents the start of the heating.

Figure 3a shows the schematic of the electric circuit to measure thermal conductivity and Fig. $3 b$ shows the zoomed-in schematic of the test section. In the setup, an ultrathin Pt wire with a length of $160 \mathrm{~mm}$ and a diameter of $20 \mu \mathrm{m}$ (aspect ratio $=8000)$ is used to eliminate the effect of conduction along the wire and ensure one-dimensional heat transfer. The test chamber is made of two concentric cylinders of diameter of $45 \mathrm{~mm}$ and $89 \mathrm{~mm}$, respectively. The tested PCM is filled in the inner cylinder where the hot wire is placed in its centerline. The outer cylinder is filled with water and is connected to a chiller for temperature control. The transient temperature of the hot wire $(\Delta T)$ is determined by measuring the electrical resistance of the hot wire using a Wheatstone bridge circuit, with high precision resistors (i.e. $R_{1}, R_{2}$ and $R_{3}$ ) at three legs of the bridge, and the hot wire with a potentiometer at the other leg. The potentiometer is used to zero the bridge circuit at the beginning of the tests. In addition to the bridge, the circuit consists of a power supply, a relay connected to a wave generator and an oscilloscope. The input voltage, $V_{s}$, and the bridge voltage, $V_{b}$, are measured with an oscilloscope. The wave generator is used to synchronize the measurement of the bridge circuit and connecting the circuit. A square wave is pre-set in the wave generator. When the square wave reaches its up edge, the relay will close the loop and meanwhile the signal will be sent to the oscilloscope to start recording the bridge voltage as a function of time. The dynamic electrical resistance of the Pt wire during the tests is calculated using the dynamic voltage recorded by the oscillosocpe as following

$$
\Delta R_{w}(t)=\frac{R_{3}}{\frac{R_{1}}{R_{1}+R_{2}}-\frac{V_{b}(t)}{V_{s}}}-\frac{R_{3}}{\frac{R_{1}}{R_{1}+R_{2}}}
$$

In the present work, the resistance of the three resistors $R_{1}, R_{2}$ and $R_{3}$ are set to the same value of $100 \Omega$. The dynamic temperature of the Pt wire is then calculated as 


$$
\frac{\Delta R_{w}(t)}{R_{w 0}}=\alpha \Delta T(t)
$$

where $\alpha$ is the temperature coefficient of resistance $\left(\alpha=0.003927 \mathrm{~K}^{-1}\right.$ for platinum [34]). The thermal conductivity of the sample is then determined using Eq. (1) with the transient temperature increase of the hot wire $\Delta T$. The hot wire setup is validated with two common materials, i.e., air and soybean oil. The measured conductivity of air is $0.0271 \mathrm{~W} /(\mathrm{m} \cdot \mathrm{K})$ at $25^{\circ} \mathrm{C}$ that is within $5 \%$ relative error with the tabulated value of $0.0257 \mathrm{~W} /(\mathrm{m} \cdot \mathrm{K})$, and the measured conductivity of soybean oil is $0.147 \mathrm{~W} /(\mathrm{m} \cdot \mathrm{K})$ at $25{ }^{\circ} \mathrm{C}$ that is within $7 \%$ relative error with the tabulated value of $0.158 \mathrm{~W} /(\mathrm{m} \cdot \mathrm{K})$ [35].

(a)

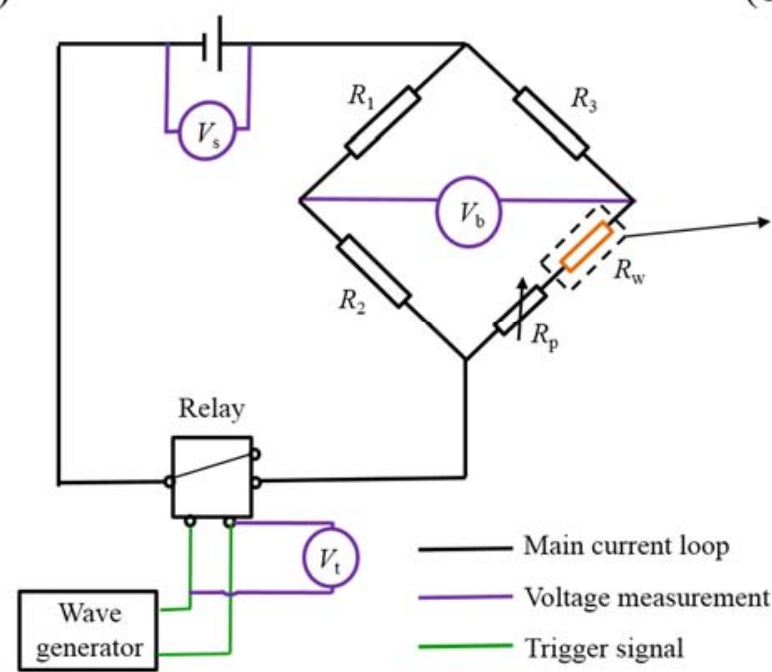

(b)

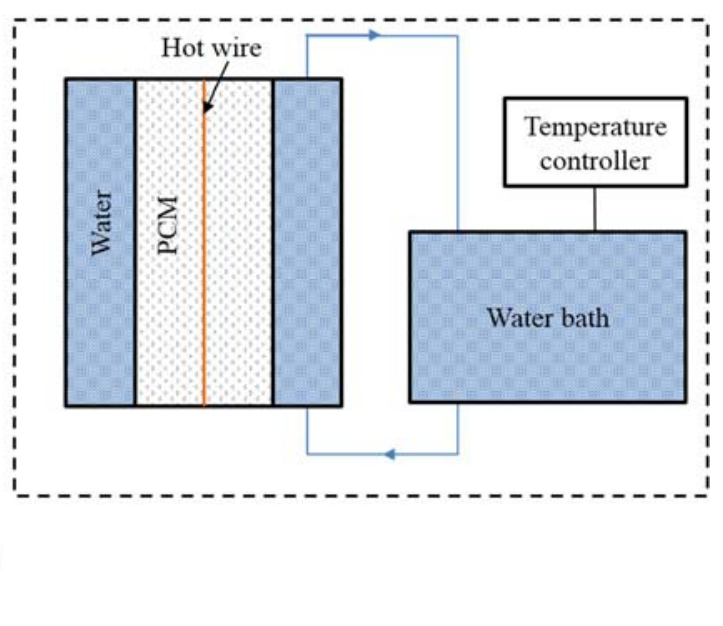

Figure 3. (a) Schematic of the electric circuit of hot wire method to measure thermal conductivity. (b) Detailed view of the test section of the hot wire setup.

\subsection{Thermal network model}

In this section, a simple thermal network model is developed for solidification in a spherical enclosure. Figure 4 shows the schematic of PCM solidifying in a spherical enclosure with an outer radius of $r_{\mathrm{o}}$ and inner radius of $r_{\mathrm{i}}$. The basic assumptions of the model are: 
i) $\mathrm{PCM}$ is a homogeneous material with a constant solidification temperature $T_{\mathrm{m}}$;

ii) Liquid PCM is initially at melting temperature $T_{\mathrm{m}}$;

iii) The sensible energy content of PCM is negligible ( Ste $<<1$ ); and

iv) Solid and liquid PCM have the same density.

For solidification in a spherical enclosure subject to convective cooling, there are three major thermal resistances that are in series: resistance due to the external convection, $R_{\text {conv, }}$ resistance due to the radial conduction through the wall, $R_{\text {wall, }}$ and resistance due to the conduction through the solidified spherical shell, $R_{\mathrm{PCM}}$, given by

$$
\begin{gathered}
R_{\text {conv }}=\frac{1}{h A} \\
R_{\text {wall }}=\frac{r_{\mathrm{o}}-r_{\mathrm{i}}}{4 \pi k_{\text {wall }} r_{\mathrm{o}} r_{\mathrm{i}}} \\
R_{\mathrm{PCM}}=\frac{r_{\mathrm{i}}-r_{\mathrm{s}}}{4 \pi k_{\mathrm{PCM}} r_{\mathrm{i}} r_{\mathrm{s}}}
\end{gathered}
$$

where $A$ is the area of the external surface of the spherical enclosure and $r_{\mathrm{s}}$ denotes the radial location of the solidification front. The temperature difference between the PCM phase change temperature, $T_{\mathrm{m}}$, and the surrounding temperature, $T_{\infty}$, induces solidification of the PCM and release of the latent heat of the PCM. The solution procedure is iterative in time. At any time step, the heat transfer rate $q$ is calculated by dividing the driving temperature difference by sum of the thermal resistances $q=\left(T_{\mathrm{m}}-T_{\infty}\right) / \sum R$. This heat transfer rate is then used to calculate the amount of solidified PCM at the end of the time step, following

$$
\dot{m}_{\text {solid }}=\frac{q}{h_{s l}}
$$

The location of solidification front at the end of time step is then updated using the mass of solidified PCM following 


$$
r_{\mathrm{s}}=\left[r_{\mathrm{i}}^{3}-\frac{3}{4} \frac{m_{\mathrm{solid}}}{\pi \rho_{\mathrm{PCM}}}\right]^{\frac{1}{3}}
$$

The solidification fraction is then $V^{*}=1-\left(r_{\mathrm{s}} / r_{\mathrm{i}}\right)^{3}$, where $V_{0}$ is the total volume of PCM. The iterations stop when $V^{*}>99.9 \%$ or the solidified fraction reaches the desired value.

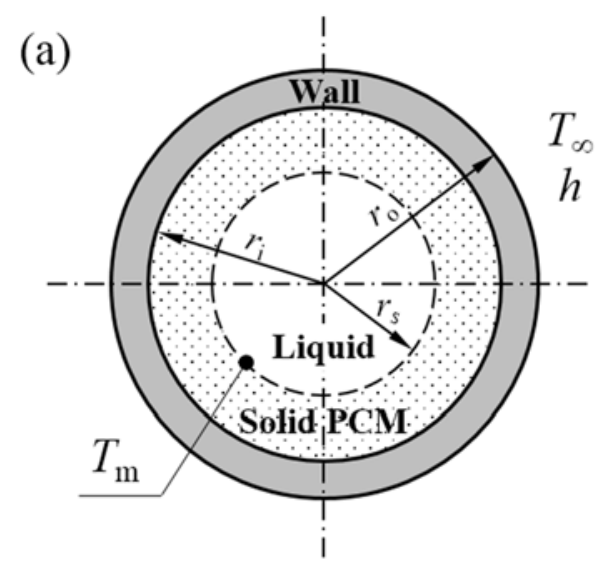

(b)

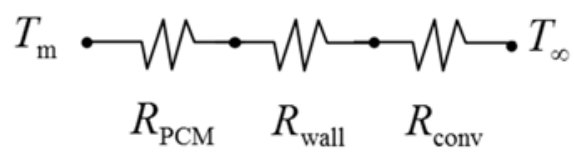

Figure 4: (a) Inward freezing of PCM within a spherical enclosure; (b) Thermal resistance network for inward freezing due to convective cooling.

Equations (4)-(6) can be non-dimensionalized by introducing the following dimensionless variables: $r^{*}=r / r_{\mathrm{o}}, R^{*}=R /\left[r_{\mathrm{o}} /\left(A k_{\mathrm{PCM}}\right)\right]$ and $\mathrm{Bi}=2 h r_{\mathrm{o}} / k_{\mathrm{PCM}}$, where $h$ is the external heat transfer coefficient. In addition, in order to focus on the most important parameters affecting the solidification subject to convective cooling, the following non-dimensionalized formulation is further simplified by considering a thin wall $\left(r_{\mathrm{o}}=r_{\mathrm{i}}\right)$ with negligible thermal resistance. Using the above dimensionless variables, the non-dimensional form of the convective and PCM thermal resistances are obtained as

$$
R_{\mathrm{conv}}^{*}=\frac{2}{\mathrm{Bi}}
$$




$$
R_{\mathrm{PCM}}^{*}=\frac{1}{r_{\mathrm{s}}^{*}}-1
$$

The evolution of solid volume fraction, $V^{*}$, versus non-dimensional time, FoSte, is obtained by non-dimensionalizing Eq. (7) to yield

$$
\frac{d V^{*}}{d \text { Ste Fo }}=\frac{3}{\frac{1}{\left(1-V^{*}\right)^{1 / 3}}-1+\frac{2}{\mathrm{Bi}}}
$$

where Ste and Fo are defined as Ste $=c_{p}\left(T_{\mathrm{m}}-T_{\infty}\right) / h_{\mathrm{s} 1}$ and $\mathrm{Fo}=k_{\mathrm{PCM}} t /\left(\rho_{\mathrm{PCM}} c_{p} r_{\mathrm{i}}^{2}\right)$ respectively.

\section{Results and Discussion}

Figure 5a shows the experimentally-determined effective thermal conductivity of eicosane with xGnPs volume fractions of $0 \%, 0.52 \%, 1.04 \%, 1.57 \%$ and $2.09 \%$ as a function of temperature obtained from the hot wire tests. Eicosane is in solid state at $23{ }^{\circ} \mathrm{C}$, and is in liquid state at $40{ }^{\circ} \mathrm{C}$ and $55^{\circ} \mathrm{C}$. The thermal conductivity of pure solid eicosane at $23{ }^{\circ} \mathrm{C}$ is 0.407 $\mathrm{W} /(\mathrm{m} \cdot \mathrm{K})$, consistent with literature [21]. As shown in Fig. 5a, the effective thermal conductivity of eicosane keeps increasing with $\mathrm{xGnP}$ volume fraction, and reaches $1.24 \mathrm{~W} /(\mathrm{m} \cdot \mathrm{K})$ with only $2.09 \mathrm{vol} \%$ of $\mathrm{xGnP}$. Furthermore, at all $\mathrm{xGnP}$ volume fractions investigated, the thermal conductivity of solid eicosane is higher than that of liquid eicosane. The crystalline structure of eicosane contributes to the higher thermal conductivity in the solid phase. It is observed that the effective thermal conductivity of eicosane in the liquid phase does not change noticeably from 40 ${ }^{\circ} \mathrm{C}$ to $45^{\circ} \mathrm{C}$, indicating that thermal conductivity is not a strong function of temperature in this range.

Figure $5 \mathrm{~b}$ shows the enhancement of thermal conductivity of eicosane, $k_{\text {eff }} / k_{\text {base }}\left(k_{\text {base }}\right.$ the thermal conductivity of pure eicosane), as a function of volume fraction of $\mathrm{xGnP}, \phi$. The blue squares and red triangles represent solid and liquid eicosane, respectively. The green circles represent the enhancement in effective thermal conductivity of a commercial paraffin PCM (IGI 1230A) from Warzoha and Fleischer [22]. The solid line represents the prediction of effective medium model of Nan et al. [36] following 


$$
\frac{k_{\mathrm{eff}}}{k_{\mathrm{base}}}=1+\frac{\varphi p}{3} \frac{k_{\mathrm{xGNP}} / k_{\text {base }}}{p+\frac{2 a_{\mathrm{K}}}{\delta} \frac{k_{\mathrm{xGNP}}}{k_{\text {base }}}}
$$

where $p$ is the aspect ratio of $\mathrm{xGnP}, a_{\mathrm{K}}$ is the Kapitza length, and $\delta$ is the thickness of $\mathrm{xGnP}$. The Kapitza resistance at the interface between graphite nanoplatelet and paraffin is $R_{\mathrm{K}} \approx 0.9 \times 10^{-7}$ $\mathrm{m}^{2} \mathrm{~K} / \mathrm{W}$ [37]. Thus, the Kapitza length is $a_{\mathrm{K}}=R_{\mathrm{K}} k_{\text {base }}=36.6 \mathrm{~nm}$. The thermal conductivity of $\mathrm{xGnP}$ adopted here is based on $\mathrm{xGnP}$ paper with $k_{\mathrm{xGnP}}=98 \mathrm{~W} /(\mathrm{m} \cdot \mathrm{K})[33]$, which is much smaller than the intrinsic thermal conductivity of $x \mathrm{GnP}$ of $2,000 \mathrm{~W} /(\mathrm{m} \cdot \mathrm{K})[38]$ due to more phononboundary scattering. As shown in Fig. 5b, both present work and Warzoha and Fleischer's data agree well with the model of Nan et al. With $\mathrm{xGnP}$ volume fraction of $2.09 \%$, the thermal conductivity increases by $205 \%$ for solid eicosane and $211 \%$ for liquid eicosane.

(a)

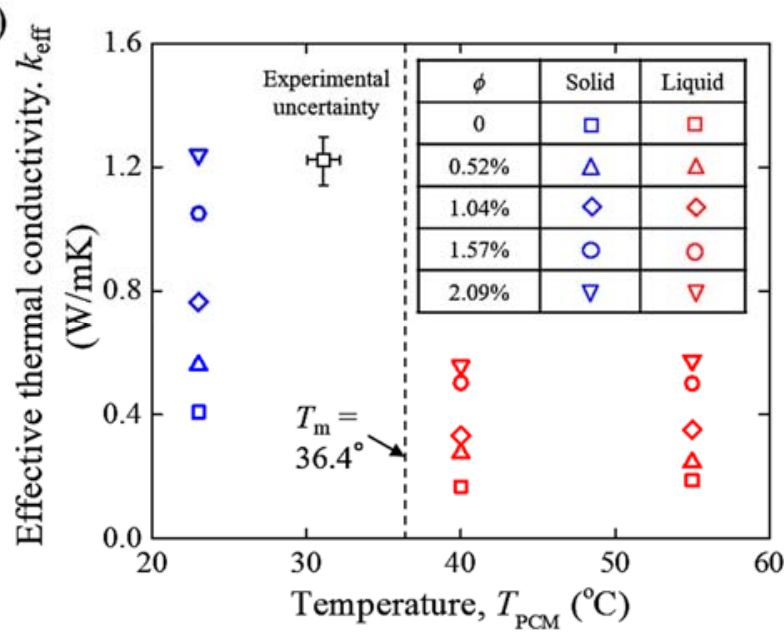

(b)

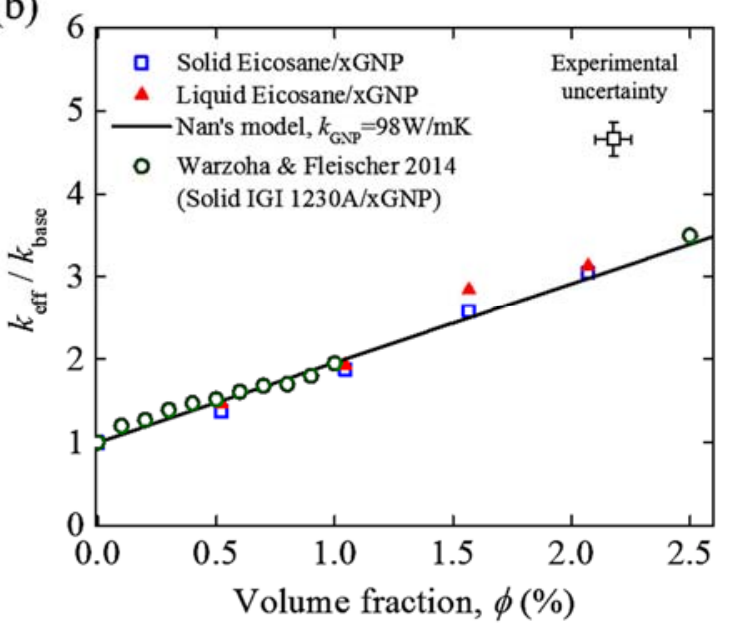

Figure 5. (a) Effective thermal conductivity of eicosane with $\mathrm{xGnP}$ as a function of temperature for various $\mathrm{xGnP}$ volume fractions, and (b) Enhancement in thermal conductivity relative to pure eicosane compared against theoretical predictions of Nan et al. [36] and experimental measurements of Warzoha and Fleischer [22].

Figure 6a shows the experimental results for solidification time, $t_{\text {sol }}$, as a function of convective subcooling, $T_{\mathrm{PCM}}-T_{\text {water }}$, for solidification of eicosane with xGnPs volume fractions 
of $0 \%, 0.52 \%, 1.04 \%, 1.57 \%$ and $2.09 \%$ in spherical enclosures with outer diameter of $38 \mathrm{~mm}$ and $50 \mathrm{~mm}$ subject to water cooling. For both enclosure sizes, the solidification time decreases with increasing subcooling and increasing $\mathrm{xGnP}$ volume fraction. The enhancement in thermal conductivity with increasing nanoadditive volume fraction leads to reduction in solidification time. For example, the thermal conductivity of additive-enhanced eicosane with $1.57 \mathrm{vol} \% \mathrm{xGnP}$ is $1.05 \mathrm{~W} /(\mathrm{m} \cdot \mathrm{K})$, which is $\sim 2.5$ times of the conductivity of pure eicosane, $0.407 \mathrm{~W} /(\mathrm{m} \cdot \mathrm{K})$. As a result, a 50\% reduction in solidification time is observed for additive-enhanced eicosane with $1.57 \mathrm{vol} \% \mathrm{xGnP}$ compared to pure eicosane. As shown in Figure 6a, for the same volume fraction of $\mathrm{xGnP}$, the solidification time increases with the diameter of the spherical enclosure. For example, in the subcooling range of $11.4-26.4{ }^{\circ} \mathrm{C}$, the solidification time of pure eicosane in the $50 \mathrm{~mm}$ sphere is about $105 \%$ greater than that in the $38 \mathrm{~nm}$ sphere. The inner diameter of the spherical enclosure (i.e. the diameter of PCM) is $32 \mathrm{~mm}$ for the $38 \mathrm{~mm}$ sphere, and $46 \mathrm{~mm}$ for the $50 \mathrm{~mm}$ sphere. Thus, the conduction length of PCM in the $50 \mathrm{~mm}$ sphere is $\sim 1.43$ times of that in the $38 \mathrm{~mm}$ sphere. The solidification time roughly following $t_{\mathrm{sol}} \propto D_{\mathrm{PCM}}^{2}$ indicates that the solidification of PCM under fixed temperature boundary is a conduction-controlled process, and natural convection does not play a significant role in the process.

It is helpful to generalize the results of the solidification tests by presenting them in terms of dimensionless numbers and compare them with the theoretical modeling. Figure $6 \mathrm{~b}$ shows the comparison between the experiment-determined and model-predicted non-dimensional solidification time, $\mathrm{Fo}_{\text {sol }}$, as a function of Ste. It is noted that $\mathrm{Fo}_{\text {sol }}$ from the experiments is determined using the inner diameter of the spherical shell, whereas the model does not need any specification of the physical dimensions as long as only the dimensionless quantities are of interest. The solid line represents the prediction of the conduction-controlled model (i.e., Eq. (11)) in the limit of $\mathrm{Bi} \rightarrow \infty$. The solid and open symbols represent the experimental results for solidification in spherical enclosures with outer diameter of $38 \mathrm{~mm}$ and $50 \mathrm{~mm}$, respectively. As shown in Fig. 6b, the solidification time from experiments is smaller than the prediction of the conduction-controlled model, which is consistent with the observation of solidification of PCM in cylindrical enclosures subject to constant temperature boundary [39,28]. The experimental solidification times in this work are determined using the thermocouple at the center and at the edge of the spherical PCM. Dendrite solidification resulting in traces of solid PCM to reach to 
the center thermocouple while some amount of liquid PCM still remains in the system may lead to the underestimation of solidification time from experiments [31]. It can also be observed from Fig. $6 \mathrm{~b}$ that the non-dimensional solidification time, $\mathrm{Fo}_{\text {sol }}$ for the $50 \mathrm{~mm}$ spherical enclosure is greater than the $38 \mathrm{~mm}$ enclosure. The size effect can also be attributed to the dendrite growth as the effect of dendrites can be more pronounced for smaller enclosure size. This trend of increasing $\mathrm{Fo}_{\text {sol }}$ with increasing enclosure size is consistent with the observation of solidification of PCM in cylindrical enclosure [28].

The conduction-controlled model is developed based on the four basic assumptions listed in Section 2.3. Here we examine the possible role of these assumptions in the deviation between the model prediction and experimental results. Firstly, the model assumes a constant solidification temperature, which neglects the possible sensible heat accumulation during the solidification process. However, the PCM in the present study has a narrow solidification range of $35-37{ }^{\circ} \mathrm{C}$, leading to a sensible heat of $\sim 4 \mathrm{~kJ} / \mathrm{kg}$ (based on solid PCM specific heat of $1.92 \mathrm{~kJ} /(\mathrm{kg} \cdot \mathrm{K}$ )), which is negligible compared to the latent heat of PCM $(\sim 247 \mathrm{~kJ} / \mathrm{kg})$. Secondly, the model assumes that the liquid PCM is initially at the melting temperature $T_{\mathrm{m}}$. In the experiments, the liquid PCM starts at a temperature $\sim 2-5{ }^{\circ} \mathrm{C}$ higher than $T_{\mathrm{m}}$, but the amount of sensible heat due to superheating is $\sim 4-10 \mathrm{~kJ} / \mathrm{kg}$, much smaller than the latent heat of PCM. Thirdly, the model assumes Ste $<<1$. The Stefan number in the experiments is within the range of 0.1-0.205. It has been shown in the literature that for Ste up to 0.235 the effect of sensible cooling of the frozen PCM is negligible [40]. Lastly, the model neglects the density difference between solid and liquid PCM. In our experiments, the density of the solid PCM is slightly $(\sim 4 \%)$ higher than that of the liquid, which should not lead to a major difference between the experiments and model predictions. The above analysis shows that these four model assumptions may contribute but not be the only root of the disagreement between the experimental results and model predictions. 
(a)

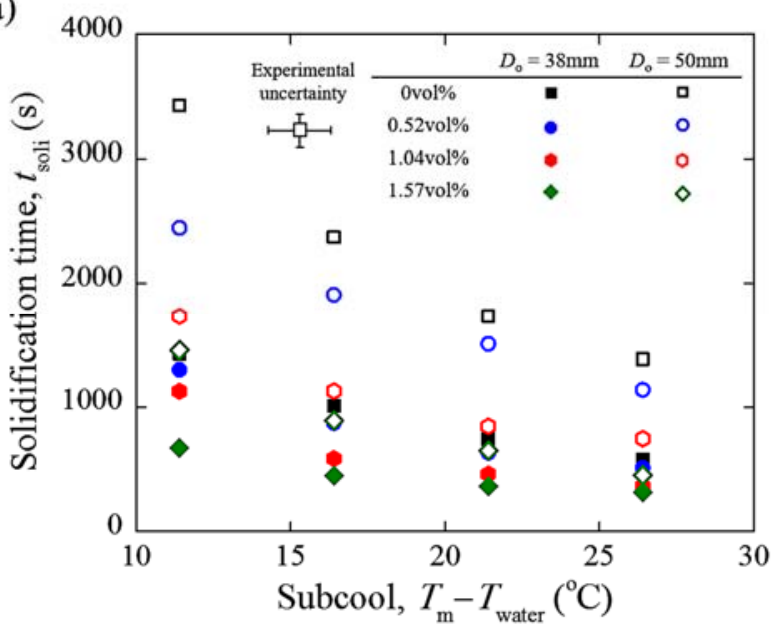

(b)

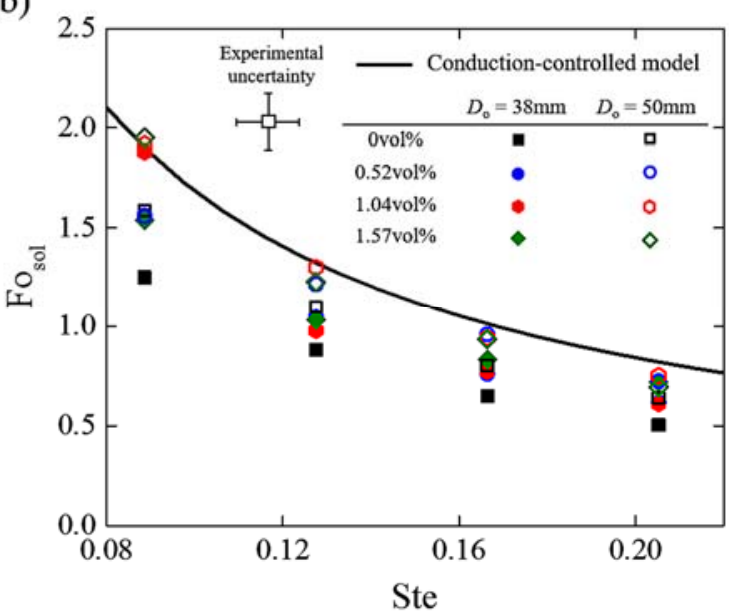

Figure 6. (a) Solidification time of eicosane with xGnP volume fractions of $0 \%, 0.52 \%, 1.04 \%$ and $1.57 \%$ subject to water cooling as a function of subcooling. (b) Comparison between experiments and model predictions for non-dimensional solidification time, $\mathrm{Fo}_{\text {sol }}$ as a function of Ste for solidification of eicosane with $\mathrm{xGnP}$ volume fractions of $0 \%, 0.52 \%, 1.04 \%, 1.57 \%$ and $2.09 \%$ in water cooling.

Figure 7a shows the experimentally-determined solidification time, $t_{\text {sol }}$, as a function of air velocity, $U_{\text {air }}$, for solidification of eicosane with $\mathrm{xGnP}$ volume fractions of $0 \%, 0.52 \%, 1.04 \%$, $1.57 \%$ and $2.09 \%$ in spherical enclosures with outer diameter of $38 \mathrm{~mm}$ and $50 \mathrm{~mm}$ subject to air cooling. For both enclosure sizes, the solidification time decreases with increasing air velocity due to enhanced external convection. Moreover, the solidification time decreases with increasing volume fraction of $\mathrm{xGnP}$ due to enhanced PCM thermal conductivity. As PCM thermal conductivity increases from $0.407 \mathrm{~W} /(\mathrm{m} \cdot \mathrm{K})$ for pure eicosane to $1.05 \mathrm{~W} /(\mathrm{m} \cdot \mathrm{K})$ for eicosane with $\mathrm{xGnP}$ volume fraction of $1.57 \%$, an average $33 \%$ reduction is observed in solidification time. It is noted that for the same enhancement in PCM thermal conductivity, $50 \%$ reduction in solidification time is obtained in water cooling. This is because while conduction resistance of solid PCM is the dominant resistance in water cooling, both the external convection resistance and the conduction resistance of solid PCM are important in air cooling. The addition of nanoadditives reduces the PCM conduction thermal resistance, but does not affect the convection resistance. 
Figure $7 \mathrm{~b}$ shows the comparison between the experimentally-determined and modelpredicted non-dimensional solidification time, $\mathrm{Fo}_{\text {sol }}$, as a function of $\mathrm{Bi}$. The solid line represents the prediction of the conduction-controlled model developed in Section 2.3. The solid and open symbols represent the experimental results for solidification in spherical enclosures with outer diameter of $38 \mathrm{~mm}$ and $50 \mathrm{~mm}$, respectively. The $\mathrm{Bi}$ number $\left(\mathrm{Bi}=2 h_{\mathrm{air}} r_{\mathrm{o}} / k_{\mathrm{PCM}}\right)$ for the experimental results is calculated using the air-side heat transfer coefficient and the measured thermal conductivity of PCM. The air-side heat transfer coefficient is calculated following $h_{\text {air }}=\mathrm{Nu} k_{\text {air }} /\left(2 r_{\mathrm{o}}\right)$, and the Nusselt number correlation for flow over a sphere is based on $\mathrm{Nu}=2+\left(0.4 \operatorname{Re}^{1 / 2}+0.06 \operatorname{Re}^{2 / 3}\right) \operatorname{Pr}^{0.4}\left(\mu / \mu_{\mathrm{s}}\right)^{1 / 4}$, where the Reynolds number is defined as $\operatorname{Re}=2 \rho_{\text {air }} U_{\text {air }} r_{\mathrm{o}} / \mu$, the Prandtl number is given by $\operatorname{Pr}=c_{\text {p,air }} \mu / k_{\text {air }}, \mu$ is the dynamic viscosity of the ambient air, and $\mu_{\mathrm{s}}$ is the dynamic air viscosity on the sphere surface.

Consistent with our results in water cooling, the experimentally-determined $\mathrm{Fo}_{\text {sol }}$ in air cooling is smaller than the model prediction. Since the distribution of convection heat transfer coefficient is not completely uniform on the outer surface of the spherical enclosure, solidification of PCM can be asymmetric in the spherical enclosure. It is thus possible that the thermocouple in the center of the spherical enclosure gets in contact with solid PCM while liquid PCM still exists elsewhere in the enclosure. This asymmetric solidification may lead to underestimation of the solidification time from experiments. It can be argued that together with dendrite solidification, the asymmetric solidification is responsible for smaller Fo sol $_{\text {than model }}$ prediction in air cooling. 


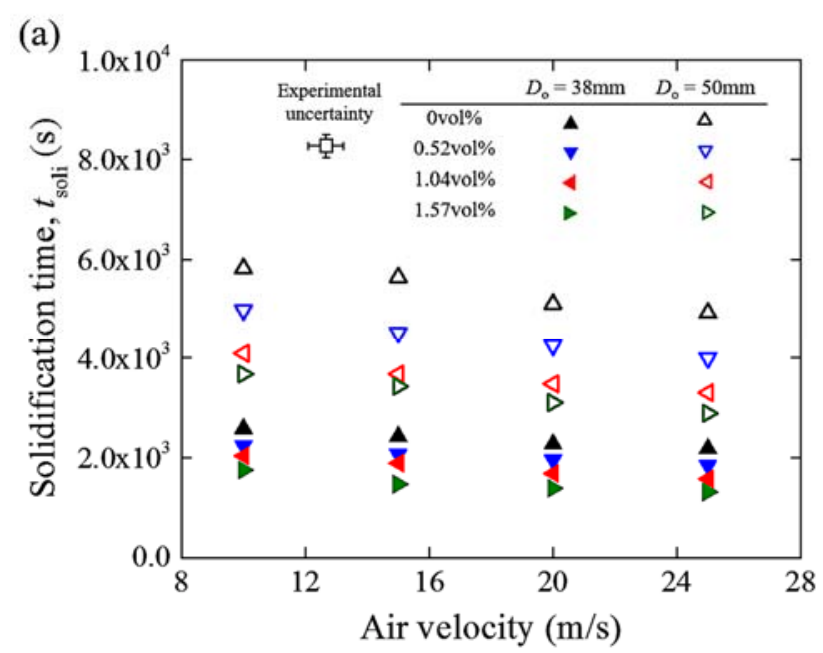

(b)

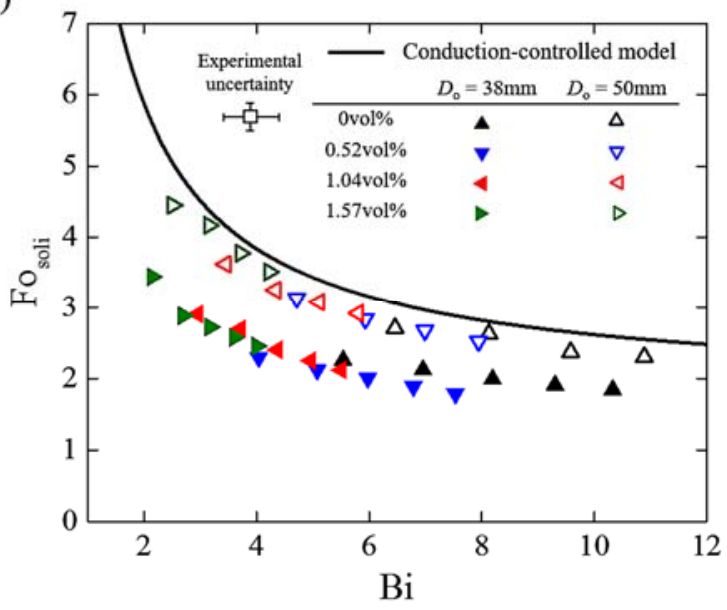

Figure 7. (a) Solidification time of eicosane with xGnP volume fractions of $0 \%, 0.52 \%, 1.04 \%$ and $1.57 \%$ in air cooling as a function of air velocity with Ste $=0.0887$. (b) Comparison between experiments and model predictions for non-dimensional solidification time, Fo ${ }_{\text {sol }}$, as a function of $\mathrm{Bi}$ for solidification of eicosane with $\mathrm{xGnP}$ of varying volume fractions in air cooling.

Figure $8 \mathrm{a}$ shows the dynamic solid fraction, $V / V_{0}$, during the solidification process of eicosane with $\mathrm{xGnP}$ of varying volume fractions solidifying in the $50 \mathrm{~mm}$ diameter spherical enclosure subject to water cooling at $T_{\text {water }}=25^{\circ} \mathrm{C}$ and air cooling at $T_{\text {air }}=25^{\circ} \mathrm{C}$ and $U_{\text {air }}=25 \mathrm{~m} / \mathrm{s}$. The product of Fourier and Stefan numbers, FoSte is used to represent the nondimensional time that incorporates the effect of thermal conductivity and subcooling. The black solid line represents the model prediction for water cooling based on Eq. (11) in the limit of $\mathrm{Bi} \rightarrow$ $\infty$. The black and green dashed lines represent the model predictions for air cooling at $U_{\text {air }}=25$ $\mathrm{m} / \mathrm{s}$ for $\mathrm{xGnP}$ volume fraction of $0 \%$ and $1.57 \%$, respectively. It is observed that the experimental results for water cooling collapse to the model prediction with constant temperature boundary, and the experimental results for air cooling lie within the range of the model predictions for the lowest and highest $\mathrm{xGnP}$ volume fractions (i.e. $0 \%$ and $1.57 \%$, respectively). The non-dimensional solidification time for air cooling is larger than water cooling due to the effect of convective resistance. 


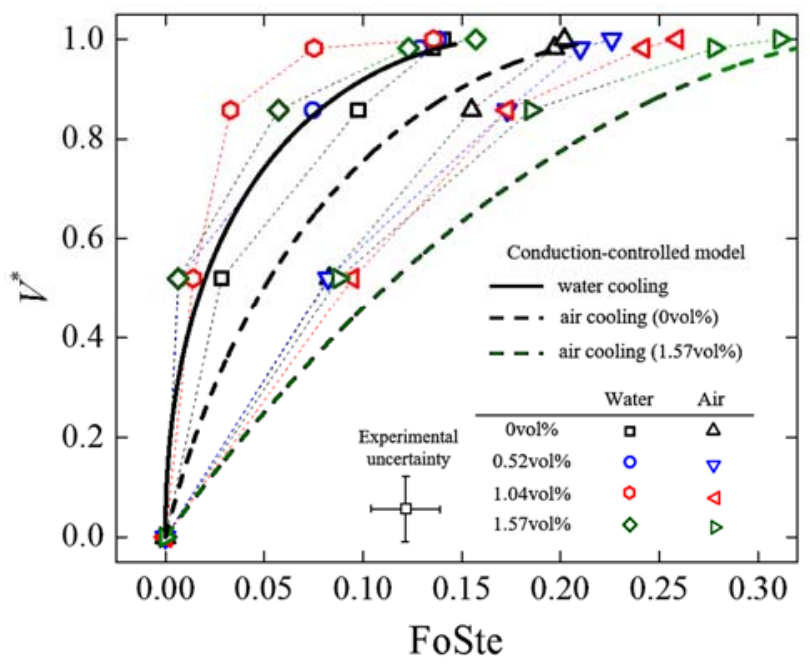

Figure 8. Comparison of experiments and model predictions for solid fraction, $V^{*}$ as a function of FoStefor solidification of eicosane with $\mathrm{xGnP}$ volume fractions of $0 \%, 0.52 \%, 1.04 \%$ and $1.57 \%$ in water at $T_{\text {water }}=25^{\circ} \mathrm{C}$ and in air at $T_{\text {air }}=25^{\circ} \mathrm{C}$ and $U_{\text {air }}=25 \mathrm{~m} / \mathrm{s}$. The model prediction is based on Eq. (11) in the limit of $\mathrm{Bi} \rightarrow \infty$ for water cooling, and Eq. (11) at $U_{\text {air }}=25 \mathrm{~m} / \mathrm{s}$ for air cooling.

As shown in Figure $7 \mathrm{~b}$ and Figure 8, the non-dimensional solidification time under convective cooling, $\mathrm{Fo}_{\text {sol }}$, is a function of $\mathrm{Bi}$, which characterizes the competition between the external convective resistance and the PCM conduction resistance. In the limit of $\mathrm{Bi} \rightarrow \infty$ (corresponding to constant temperature boundary), $\left.\mathrm{Fo}_{\text {sol }} \rightarrow \mathrm{Fo}_{\mathrm{sol}}\right|_{\mathrm{Bi} \rightarrow \infty}$. As for finite values of $\mathrm{Bi}$ (corresponding to convective boundary with finite heat transfer coefficient), $\mathrm{Fo}_{\mathrm{sol}}>\left.\mathrm{Fo}_{\mathrm{sol}}\right|_{\mathrm{Bi} \rightarrow \infty}$ due to the additional convective resistance. By fitting the results of the numerical model, the following simple correlation is obtained

$$
\frac{\mathrm{Fo}_{\text {sol }}}{\left.\mathrm{Fo}_{\mathrm{sol}}\right|_{\mathrm{Bi} \rightarrow \infty}}=1+\frac{4.5}{\mathrm{Bi}}
$$

Equation (13) can be used as a tool to calculate the solidification time of PCM freezing in spherical enclosures subject to convective cooling with known $\left.\mathrm{Fo}_{\mathrm{sol}}\right|_{\mathrm{Bi} \rightarrow \infty}$. The Fourier number 
for constant temperature boundary, $\left.\mathrm{Fo}_{\mathrm{sol}}\right|_{\mathrm{Bi} \rightarrow \infty}$, can be solved from Eq. (11) in the limiting case of $\mathrm{Bi} \rightarrow \infty$. And the factor $(1+4.5 / \mathrm{Bi})$ can be used to unify the experimental results of solidification time for different cooling conditions.

Figure 9 shows the comparison between the experiments and model predictions for the scaled non-dimensional solidification time, $\mathrm{Fo}_{\text {sol }} /(1+4.5 / \mathrm{Bi})$, as a function of Ste for solidification of eicosane with $\mathrm{xGnP}$ volume fractions of $0 \%, 0.52 \%, 1.04 \%, 1.57 \%$ and $2.09 \%$ in water and air. For solidification experiments in air, the non-dimensional solidification time $\mathrm{Fo}_{\text {sol }}$ is scaled with $1+4.5 / \mathrm{Bi}$, based on Eq. (13), which relates $\mathrm{Fo}_{\text {sol }}$ for convective cooling to the non-dimensional solidification time for constant temperature cooling, $\left.\mathrm{Fo}_{\mathrm{sol}}\right|_{\mathrm{Bi} \rightarrow \infty}$. It is observed that the experimental results for water cooling overlap with the results for air cooling, proving that the scaling factor from Eq. (13) successfully unifies the results for water and air cooling. And despite of the cooling conditions, the scaled dimensionless solidification time $\mathrm{Fo}_{\text {sol }} /(1+4.5 / \mathrm{Bi})$ monotonically decreases with increasing Ste . 


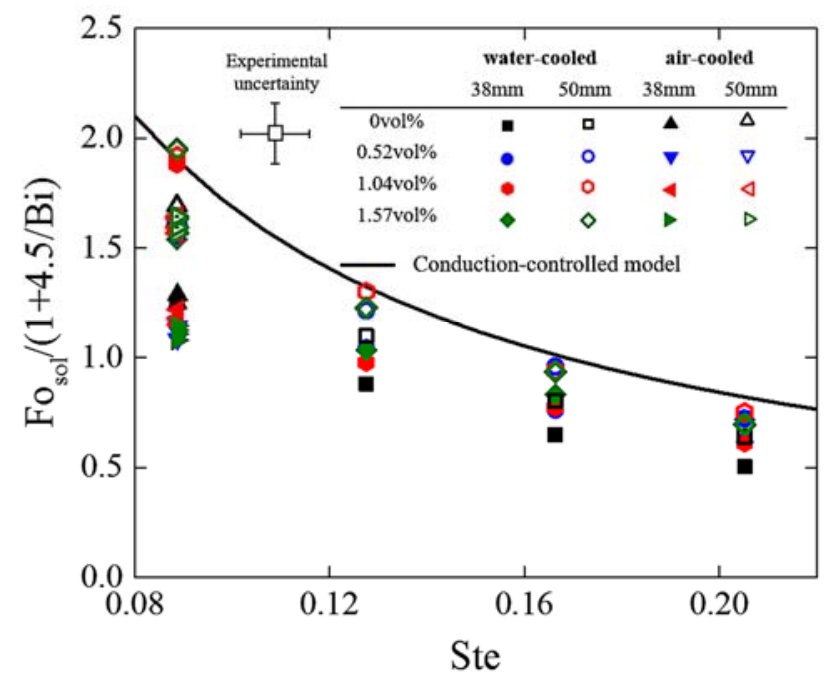

Figure 9. Comparison between the experiments and model predictions for the scaled nondimensional solidification time, $\mathrm{Fo}_{\text {sol }} /(1+4.5 / \mathrm{Bi})$ as a function of Ste.

\section{Conclusion}

In the present work, the solidification of PCM with $\mathrm{xGnP}$ volume fractions of $0 \%, 0.52 \%$, $1.04 \%, 1.57 \%$ and $2.09 \%$ in spherical enclosures subject to air and water cooling has been investigated through experiments and modeling. The experimentally-determined solidification time is $\sim 30 \%$ smaller than the prediction of the simple thermal network model due to possible asymmetric and dendritic solidification, as well as natural convection inside the enclosure. The experiments show that the solidification time decreases with increasing subcooling and increasing external heat transfer coefficient. Furthermore, the solidification time decreases with increasing volume fraction of $\mathrm{xGnP}$ due to the $\mathrm{xGnP}$-induced enhancement in thermal conductivity of PCM. The reduction in solidification time is more pronounced in water cooling than air cooling because the PCM conduction resistance limits the heat transfer in water cooling, while external convective resistance is comparable with PCM conduction resistance in air cooling. Based on the conduction-controlled model, a simple correlation for the scaled nondimensional solidification time, $\mathrm{Fo}_{\mathrm{sol}} /\left.\mathrm{Fo}_{\mathrm{sol}}\right|_{\mathrm{Bi} \rightarrow \infty}=1+4.5 / \mathrm{Bi}$, has been developed to incorporate 
the effect of external heat transfer coefficient, so as to unify the experimental results for water and air cooling.

\section{Acknowledgements}

Support for this work was provided by the National Science Foundation (NSF) under award number 1357918 and by the Electric Power Research Institute (EPRI) under contract number 10002061.

\section{References}

[1] N.G. Deen, J.A.M. Kuipers, Direct numerical simulation of fluid flow accompanied by coupled mass and heat transfer in dense fluid-particle systems, Chem. Eng. Sci. 116 (2014) 645-656. doi:10.1016/j.ces.2014.05.036.

[2] J.P. Bédécarrats, J. Castaing-Lasvignottes, F. Strub, J.P. Dumas, Study of a phase change energy storage using spherical capsules. Part I: Experimental results, Energy Convers. Manag. 50 (2009) 2537-2546. doi:10.1016/j.enconman.2009.06.004.

[3] T.L. Rogers, J. Hu, Z. Yu, K.P. Johnston, R.O. Williams, A novel particle engineering technology: spray-freezing into liquid, Int. J. Pharm. 242 (2002) 93-100. doi:10.1016/S0378-5173(02)00154-0.

[4] Y. Sun, M. McCarthy, Y.I. Cho, P. Boettcher, H. Hu, B. Shi, Q. Xie, Systems and Methods of Using Phase Change Material in Power Plants, (2015).

[5] M. Delgado, A. Lázaro, J. Mazo, B. Zalba, Review on phase change material emulsions and microencapsulated phase change material slurries: Materials, heat transfer studies and applications, Renew. Sustain. Energy Rev. 16 (2012) 253-273.

[6] H. Shabgard, H. Hu, P.A. Boettcher, M. McCarthy, Y. Sun, Heat transfer analysis of PCM slurry flow between parallel plates, Int. J. Heat Mass Transf. 99 (2016) 895-903. doi:10.1016/j.ijheatmasstransfer.2016.04.020.

[7] L.C. Tao, Generalized numerical solutions of freezing a saturated liquid in cylinders and spheres, AIChE J. 13 (1967) 165-169. doi:10.1002/aic.690130130.

[8] R.I. Pedroso, G.A. Domoto, Inward spherical solidification-solution by the method of strained coordinates, Int. J. Heat Mass Transf. 16 (1973) 1037-1043. doi:10.1016/00179310(73)90042-2.

[9] K.A.. Ismail, J.. Henríquez, Solidification of pcm inside a spherical capsule, Energy Convers. Manag. 41 (2000) 173-187. doi:10.1016/S0196-8904(99)00101-6.

[10] J. Hill, A. Kucera, Freezing a saturated liquid inside a sphere, Int. J. Heat Mass Transf. (1983) 1631-1637. http://dx.doi.org/10.1016/S0017-9310(83)80083-0

[11] T. Wu, H. Liaw, Y. Chen, Thermal effect of surface tension on the inward solidification of 
spheres, Int. J. Heat Mass Transf. (2002) 2055-2065 http://dx.doi.org/10.1016/S00179310(01)00313-1.

[12] S. Lin, Z. Jiang, An improved quasi-steady analysis for solving freezing problems in a plate, a cylinder and a sphere, J. Heat Transfer. (2003) 1123-1128. 10.1115/1.1622719.

[13] D. Riley, F. Smith, G. Poots, The inward solidification of spheres and circular cylinders, Int. J. Heat Mass. (1974) 1507-1516. http://dx.doi.org/10.1016/0017-9310(74)90061-1

[14] S.W. McCue, B. Wu, J.M. Hill, Classical two-phase Stefan problem for spheres, Proc. R. Soc. A Math. Phys. Eng. Sci. 464 (2008) 2055-2076. doi:10.1098/rspa.2007.0315.

[15] C.W. Chan, F.L. Tan, Solidification inside a sphere-an experimental study, Int. Commun. Heat Mass Transf. 33 (2006) 335-341. doi:10.1016/j.icheatmasstransfer.2005.10.010.

[16] E. Assis, G. Ziskind, R. Letan, Numerical and Experimental Study of Solidification in a Spherical Shell, J. Heat Transfer. 131 (2009) 024502. doi:10.1115/1.2993543.

[17] I.W. Eames, K.T. Adref, Freezing and melting of water in spherical enclosures of the type used in thermal (ice) storage systems, Appl. Therm. Eng. 22 (2002) 733-745. doi:10.1016/S1359-4311(02)00026-1.

[18] H. Koizumi, Time and spatial heat transfer performance around an isothermally heated sphere placed in a uniform, downwardly directed flow (in relation to the enhancement of latent heat storage rate in a spherical capsule), Appl. Therm. Eng. 24 (2004) 2583-2600. doi:10.1016/j.applthermaleng.2004.03.011.

[19] H. Ettouney, I. Alatiqi, M. Al-Sahali, K. Al-Hajirie, Heat transfer enhancement in energy storage in spherical capsules filled with paraffin wax and metal beads, Energy Convers. Manag. 47 (2006) 211-228. doi:10.1016/j.enconman.2005.04.003.

[20] J. Fukai, Y. Hamada, Y. Morozumi, O. Miyatake, Effect of carbon-fiber brushes on conductive heat transfer in phase change materials, Int. J. Heat Mass Transf. 45 (2002) 4781-4792. doi:10.1016/S0017-9310(02)00179-5.

[21] X. Fang, L.-W. Fan, Q. Ding, X. Wang, X.-L. Yao, J.-F. Hou, Z.-T. Yu, G.-H. Cheng, Y.C. Hu, K.-F. Cen, Increased Thermal Conductivity of Eicosane-Based Composite Phase Change Materials in the Presence of Graphene Nanoplatelets, Energy \& Fuels. 27 (2013) 4041-4047. doi:10.1021/ef400702a.

[22] R.J. Warzoha, A.S. Fleischer, Effect of graphene layer thickness and mechanical compliance on interfacial heat flow and thermal conduction in solid-liquid phase change materials., ACS Appl. Mater. Interfaces. 6 (2014) 12868-76. doi:10.1021/am502819q.

[23] H. Ji, D.P. Sellan, M.T. Pettes, X. Kong, J. Ji, L. Shi, R.S. Ruoff, Enhanced thermal conductivity of phase change materials with ultrathin-graphite foams for thermal energy storage, Energy Environ. Sci. 7 (2014) 1185. doi:10.1039/c3ee42573h.

[24] S. Kalaiselvam, R. Parameshwaran, S. Harikrishnan, Analytical and experimental investigations of nanoparticles embedded phase change materials for cooling application in modern buildings, Renew. Energy. 39 (2012) 375-387. doi:10.1016/j.renene.2011.08.034.

[25] P. Chandrasekaran, M. Cheralathan, V. Kumaresan, R. Velraj, Solidification behavior of 
water based nanofluid phase change material with a nucleating agent for cool thermal storage system, Int. J. Refrig. (2014). doi:10.1016/j.ijrefrig.2013.12.017.

[26] V. Kumaresan, P. Chandrasekaran, M. Nanda, A.K. Maini, R. Velraj, Role of PCM based nanofluids for energy efficient cool thermal storage system, Int. J. Refrig. 36 (2013) 1641-1647. doi:10.1016/j.ijrefrig.2013.04.010.

[27] A.A. Altohamy, M.F. Abd Rabbo, R.Y. Sakr, A.A.A. Attia, Effect of water based A12O3 nanoparticle PCM on cool storage performance, Appl. Therm. Eng. 84 (2015) 331-338. doi:10.1016/j.applthermaleng.2015.03.066.

[28] M. Mahamudur Rahman, H. Hu, H. Shabgard, P. Boettcher, Y. Sun, M. McCarthy, Experimental Characterization of Inward Freezing and Melting of Additive-Enhanced Phase-Change Materials Within Millimeter-Scale Cylindrical Enclosures, J. Heat Transfer. 138 (2016) 072301. doi:10.1115/1.4033007.

[29] S. Yu, X. Wang, D. Wu, Self-Assembly Synthesis of Microencapsulated n-Eicosane Phase-Change Materials with Crystalline-Phase-Controllable Calcium Carbonate Shell, Energy \& Fuels. 28 (2014) 3519-3529. doi:10.1021/ef5005539.

[30] C. Vélez, M. Khayet, J.M. Ortiz de Zárate, Temperature-dependent thermal properties of solid/liquid phase change even-numbered n-alkanes: n-Hexadecane, n-octadecane and neicosane, Appl. Energy. 143 (2015) 383-394. doi: 10.1016/j.apenergy.2015.01.054.

[31] M. Rahman, H. Hu, Dendrite Growth during Freezing of Millimeter-Scale Eicosane Droplets, J. Heat Transfer (2015) 080905. doi: 10.1115/1.4030446.

[32] A. Faghri, Y. Zhang, Transport phenomena in multiphase systems, (2006) 967.

[33] J. Xiang, L.T. Drzal, Thermal conductivity of exfoliated graphite nanoplatelet paper, Carbon N. Y. 49 (2011) 773-778. doi:10.1016/j.carbon.2010.10.003.

[34] C. Loughlin, Sensors for Industrial Inspection, Springer Science \& Business Media, 2012.

[35] N.B. Vargaftik, Handbook of Thermal Conductivity of Liquids and Gases, CRC Press, 1993.

[36] C.-W. Nan, G. Liu, Y. Lin, M. Li, Interface effect on thermal conductivity of carbon nanotube composites, Appl. Phys. Lett. 85 (2004) 3549-3551. doi:doi:10.1063/1.1808874.

[37] M. Shtein, R. Nadiv, M. Buzaglo, K. Kahil, O. Regev, Thermally Conductive GraphenePolymer Composites: Size, Percolation, and Synergy Effects, Chem. Mater. 27 (2015) 2100-2106. doi:10.1021/cm504550e.

[38] A.A. Balandin, Thermal properties of graphene and nanostructured carbon materials., Nat. Mater. 10 (2011) 569-81. doi:10.1038/nmat3064.

[39] E.M. Sparrow, J.W. Ramsey, R.G. Kemink, Freezing Controlled by Natural Convection, J. Heat Transfer. 101 (1979) 578. doi:10.1115/1.3451040.

[40] E.D. Larson, E.M. Sparrow, Effect of Inclination on Freezing in a Sealed Cylindrical Capsule, J. Heat Transfer. 106 (1984) 394. doi:10.1115/1.3246685. 